\title{
ARTIGO
}

DOI: https://doi.org/10.22481/praxis.v15i31.4683

\section{RELATO DE EXPERIÊNCIA COMO DOCENTE NA ESCOLA ESTADUAL INDÍGENA RIACHUELO}

\author{
REPORT OF THE TEACHING EXPERIENCE AT THE INDIAN STATE SCHOOL \\ RIACHUELO
}

\section{RELATO DE EXPERIENCIA COMO DOCENTE EN LA ESCUELA ESTATAL INDÍGENA RIACHUELO}

Paulo Weverton Soares Cizino de Paiva Universidade Estadual de Roraima - Brasil

\author{
Maristela Bortolon de Matos \\ Instituto Federal de Educação, Ciência e Tecnologia de Roraima - Brasil \\ Universidade Estadual de Roraima - Brasil
}

Resumo: Este artigo trata-se de um relato de experiência vivenciado por dois anos como professor das disciplinas de História e Biologia na Escola Estadual Indígena Riachuelo, localizada na comunidade indígena do Sucuba, município do Alto Alegre, Estado de Roraima. Para o processo de produção e conclusões do presente artigo, fez-se necessário conhecer as bases legais que orientam a educação escolar indígena e realizar uma reflexão da minha prática pedagógica aplicada, considerando meu desconhecimento enquanto era docente na referida escola. Esse artigo tem como objetivo relatar como eram utilizados os materiais didáticos na organização das aulas. A pesquisa está fundamentada na Lei de Diretrizes e Bases - 9394/96, que trouxe em seu texto algumas garantias legais para as comunidades indígenas, entre elas a elaboração e publicação de material didático específico e diferenciado, no Referencial Curricular Nacional - RCNEI para Escolas Indígenas que traz subsídios para elaboração dos materiais didáticos das escolas indígenas, bem como em autores que produziram conhecimentos e contribuições sobre essa temática Barros (2015), Bendazolli (2011), dentre outros. Após os anos de docência e convívio com aquela comunidade conclui-se que os materiais didáticos que foram utilizados nas aulas não eram adequados para aquela realidade bem como não seguiam as orientações do RCNEI e da própria LDB.

Palavras chaves: Educação escolar indígena. Material didático. Referencial curricular nacional para escolas indígenas.

Abstract: This research is about a report experienced for two years as a history and Biology teacher at the Escola Estadual Indígena Riachuelo, in the indigenous community of Sucuba, Alto Alegre county, Roraima. In the production process and conclusions of this article, it became necessary to know the legal basis that would orient the indigenous school education and conduct it to a reflection of my applied pedagogical practice, considering my unawareness during the period I taught at the mentioned school. This article aims to report how the didactic materials were used in the organization of the 
classes. The research is substantiated by the Lei de Diretrizes e Bases - 9394/96, which brought in its text some legal guarantees to the indigenous communities, including the elaboration and publication of special didactic material, in the National Curricular Referential to the indigenous schools that brings allowance to those material's elaboration, as well as authors who produced knowledge and contributed to the thematic, Barros (2015), Bendazolli (2011), among others. After the years of teaching coexistence with that community, it is concluded that the didactic materials used in the classes were not adequate to that reality, but also did not follow the RCNEI and LDB orientations.

Key-words: Indigenous school education. Didactic material. National curricular material for indigenous schools

Resumen: Este artículo se trata de un relato de experiencia vivido por dos años como profesor de las asignaturas de Historia y Biología en la escuela Estatal Indígena Riachuelo, ubicada en la comunidad indígena de Sucuba, en el condado de Alto Alegre, Estado de Roraima. Para el proceso de producción y conclusiones del presente artículo, se hizo necesario conocer las bases legales que orientan la educación escolar indígena y realizar una reflexión de mi práctica pedagógica aplicada, considerando mi desconocimiento mientras era docente en a referida escuela. Ese artículo tiene como objetivo relatar cómo eran utilizados los materiales didácticos en la organización de las clases. La investigación está fundamentada en la Ley de Directrices y Bases- 9394/96, que trajo en su texto algunas garantías legales para las comunidades indígenas, entre ellas la elaboración y publicación de material didáctico específico y diferenciado en el Referencial Curricular Nacional RCNEI para Escuelas Indígenas que trae subsidios para elaboración de los materiales didácticos de las escuelas indígenas, así como en autores que produjeran conocimientos y contribuciones sobre esa temática de Barros (2015), Bendazolli (2011), entre otros. Seguido los años de docencia y convivencia con aquella comunidad se concluyó que los materiales didácticos que fueran utilizados en las clases no eran adecuados para aquella realidad así como no seguían las orientaciones del RCNEI y de la propia LDB.

Palabras claves: Educación Escolar indígena. Material didáctico. Referencial Curricular Nacional para escuelas indígenas

\section{Introdução}

Apesar de morar em um Estado com grande diversidade cultural nunca tive uma preocupação com as reivindicações indígenas, pelo contrário, até poucos anos não conseguia compreender tais reivindicações, dentre elas demarcações de terras indígenas. Entendia que um dos motivos que atrapalhavam o desenvolvimento do Estado de Roraima era o grande número de terras indígenas, dado esse comprovado pelo censo (2010) que indica $46 \%$ do território roraimense são terras indígenas.

No ano de 2007 a Secretaria Estadual de Educação do Estado de Roraima publicou edital para contratação de professores para atuarem nas Escolas Estaduais Indígenas. Relacionado a esse concurso a Organização dos Professores Indígenas de Roraima - OPIR, juntamente com o Ministério Público Federal - MPF, Ministério Público do Trabalho - MPT e pelo Ministério Público Estadual - MPE ajuizaram ação civil pública com pedido de liminar 
para suspenção da realização do concurso público. Dentre a justificativa para tal suspensão estavam a exigência que fosse encaminhado à Assembleia Legislativa do Estado de Roraima no prazo máximo de 60 dias, projeto de lei de criação da carreira específica do magistério indígena, estabelecendo o quantitativo de vagas iniciais, que deveriam ser providas através de concurso público específico para professores indígenas, que atendessem ao disposto no artigo 65 da Lei Complementar no 41/2001.

Essas entidades compreendiam que não índios não poderiam participar do concurso público, e tal entendimento me prejudicava e mais uma vez fiz voz contra as exigências das comunidades indígenas, que para mim soavam como absurdas.

Posteriormente em 2008 a liminar que impedia a realização do concurso é cassada, e finalmente o concurso foi realizado.

Tive o mérito de ser aprovado e no ano 2009 fui nomeado para o cargo de professor de educação física para atuar nas escolas estaduais indígenas de Roraima, entendo que a partir dessa data houve uma mudança da minha visão etnocêntrica em relação aos povos indígenas, pois o convívio com os indígenas fez com que despertasse o interesse pelas suas reivindicações históricas como a valorização de suas culturas e demarcações de terra.

Durante séculos a educação escolar indígena foi marginalizada, desde o período colonial onde foi implementado uma política de integração dos povos indígenas que se constituía desde uma ação catequética e jesuíta. Durante o Império, predomina essa mesma perspectiva que se estende para a República, na política do SPI e FUNAI. Sendo assim, com a implementação dessa política, os indígenas estariam sujeitos ao desaparecimento, posto que seriam integrados à sociedade nacional.

Segundo Barros (2015, p.37) “desenvolveu-se no Brasil um sistema de educação para os nativos a fim de integrá-los, instruí-los e dominá-los culturalmente", o autor complementa afirmando que a escola chegou para os indígenas impondo-se por meio de diferentes modelos e formas, cumprindo objetivos e funções diversas. Ela sempre esteve presente ao longo de toda história de relacionamento de povos indígenas com representantes do poder colonial e, posteriormente, com representantes do Estado-nação.

Cohn (2005) afirma que a intenção da escola era de salvação do gentio - salvação de si mesmo, seja em sua alma e daí a catequese ou a evangelização, seja em seus modos e daí projetos de civilização. Portanto segundo Cohn (2005, p. 486), "na maior parte dessa longa história, aos índios eram oferecidos serviços educacionais para mudar o que são e para serem integrados à sociedade que os envolvem”. 
A partir da década de 1970 eclodiu vários movimentos que reivindicavam uma Política Pública de Educação Escolar Indígena, balizada no respeito à língua e à cultura indígena, bem como a formação de índios para as escolas indígenas.

Em 1987 foi realizado no Rio de Janeiro o Encontro Nacional de Educação Indígena, participaram desse encontro 70 profissionais, entre índios, educadores, antropólogos e linguistas, representando 27 entidades civis, universidades e órgãos públicos. Grupioni (2008, p. 40) aponta que desse encontro "surgiu o primeiro documento público a propor que o Ministério da Educação e o Ministério da Cultura assumissem responsabilidades na gestão da educação indígena no país e a falar expressamente na constituição de uma política nacional de educação indígena".

Barros (2015) aponta que outros fatores importantes aconteceram na história da educação escolar para os índios, como a criação dos núcleos de estudo e pesquisa nas universidades, o que proporcionou a elaboração de propostas educacionais e a organização de eventos técnico científicos. Segundo o autor destacam-se o Núcleo de Estudos Indigenistas do Departamento de Letras da Universidade Federal de Pernambuco; o Núcleo de Educação Indígena de Roraima; o Núcleo de Educação Indígena de Mato Grosso; o Núcleo de Estudos e Educação Indígena de Belém; o Seminário Permanente de Educação e Estudos Indígenas da Universidade Federal do Rio de Janeiro; e o MARI - Grupo de Educação Indígena da Universidade de São Paulo.

Percebe-se que as discussões sobre o direito de uma Educação Escolar Indígena, deixam de ser locais ou regionais e ganham grande proporção passando a ser a nível nacional. Pesquisadores de grandes instituições educacionais corroboram na elaboração de propostas de educação intercultural que venha a contemplar os povos indígenas do Brasil.

A constituição de 1988 trouxe em seu texto uma nova visão no que diz respeito às comunidades indígenas. Abriu-se caminho para uma educação escolar especifica e diferenciada e o reconhecimento de índio perante a sociedade. No título VIII - Da Ordem Social -, capitulo III - Seção Educação -, em seu art. 210, encontramos: "Serão fixados conteúdos mínimos para o ensino fundamental, de maneira a assegurar formação básica comum e respeito aos valores culturais e artísticos, nacionais e regionais".

A Lei de Diretrizes e Bases 9394/96, no Título VIII - Das Disposições Gerais, art. 79, $\S 2^{\circ}$ diz: Os programas a que se refere este artigo, incluídos nos Planos Nacionais de Educação, terão os seguintes objetivos: 
I - fortalecer as práticas socioculturais e a língua materna de cada comunidade indígena;

II - manter programas de formação de pessoal especializado, destinado à educação escolar nas comunidades indígenas;

III - desenvolver currículos e programas específicos, neles incluindo os conteúdos culturais correspondentes às respectivas comunidades;

IV - elaborar e publicar sistematicamente material didático específico e diferenciado.

Diante do exposto, este artigo tem como objetivo analisar mais especificamente, o inciso IV do art. 79 da LDB, ou seja, pretende-se relatar como se dava a utilização dos materiais didáticos no contexto escolar nos dois anos de docência na Escola Estadual Indígena Riachuelo.

Portando, fez-se necessário um estudo de natureza qualitativa que segundo Minayo (2009, p. 21) essa pesquisa "trabalha com o universo dos significados, dos motivos, das aspirações, das crenças, dos valores e das atitudes", tendo por base uma revisão de literatura que segundo Duarte e Furtado (2015, p.28) “é um estudo sistematizado desenvolvido a partir do material já produzido e publicado para outras finalidades, constituindo-se em fonte secundaria para o pesquisador".

\section{Aspectos históricos da educação escolar indígena brasileira}

Se tivéssemos que resumir a história da educação escolar indígena até meados dos anos 80 em uma única palavra, essa palavra seria integração. Isso mesmo, durante séculos a proposta de educação para os povos indígenas era de integração a sociedade civilizada, devese entender sociedade civilizada os não-índios.

Ao longo da história vários projetos de catequização e evangelização foram destinados aos povos indígenas, sendo que tais projetos tinham como objetivo a integração dos indígenas a sociedade que os rodeava.

Como afirma o parecer 14/99, do colegiado da Câmara do Ensino básico do Conselho Nacional de Educação sobre o Referencial Curricular Nacional para as Escolas indígenas (BRASIL, 1998a, p.9):

A introdução da escola para os povos indígenas é concomitante ao início do processo de colonização do país. Num primeiro momento a escola aparece como instrumento privilegiado para catequese, depois para formar mão de 
obra e, por fim, para incorporar os índios definitivamente à Nação como trabalhadores nacionais desprovidos de atributos étnicos ou culturais.

O Estado até que reconhecia a diferença cultura dos povos indígenas, mas entendia que para se tornarem brasileiros se deveria anular essas diferenças. Tal ideia está explicita no Referencial Curricular Nacional para as Escolas Indígenas

A política integracionista começava por reconhecer a diversidade das
sociedades indígenas que havia no país, mas apontava como ponto de
chegada o fim dessa diversidade. Toda diferenciação étnica seria anulada ao
se incorporarem os índios à sociedade nacional. Ao se tornarem brasileiros,
tinham que abandonar sua própria identidade. O Estado brasileiro pensava
uma "escola para os índios" que tornasse possível a sua homogeneização. A
escola deveria transmitir os conhecimentos valorizados pela sociedade de
origem europeia. Nesse modelo, as línguas indígenas, quando consideradas,
deviam servir apenas de tradução e como meio para tornar mais fácil a
aprendizagem da língua portuguesa e de conteúdos valorizados pela cultura
nacional. (BRASIL, 1998a, p. 26-27).

Em meados da década de 1970, esse projeto de educação integracionista proposto aos povos indígenas começa a sofrer uma grande resistência conforme aponta Barros (2015, p. 4243) "as mobilizações sociais e políticas dos povos indígenas na década de 70 deram origem, mais tarde, na década de 80 , à criação da primeira organização representativa dos índios do Brasil, denominada União das Nações Indígenas - UNI".

Essa mudança de rumo começa a se concretizar com a promulgação da Constituição Federal de 1988. Muda-se o objetivo da educação escolar indígena, deixa de ser integracionista e passa para uma educação diferenciada. A partir desse momento a escola deve respeitar sua língua, sua cultura e seus processos próprios de aprendizagem.

No que diz respeito a educação diferenciada o Referencial Curricular Nacional das Escolas Indígenas - RCNEI, indica algumas características da Educação Escolar Indígena. As características indicadas são: comunitária, intercultural, bilíngue ou multilíngue, específica e diferenciada.

Comunitária porque como o próprio referencial afirma, a educação escolar será "conduzida pela comunidade indígena, de acordo com seus projetos, suas concepções e seus princípios" Brasil (1998, p.22). É a própria comunidade em suas reuniões gerais que definiram calendário escolar, os conteúdos a serem trabalhos, bem como objetivos e processos avaliativos. 
Intercultural porque deve "estimular o entendimento e o respeito entre seres humanos de identidades étnicas diferentes, ainda que se reconheça que tais relações vêm ocorrendo historicamente em contextos de desigualdade social e política” Brasil (1998, p.22).

Bilíngue ou multilíngue porque segundo o RCNEI “a organização política, os projetos de futuro, enfim, a reprodução sociocultural das sociedades indígenas é, na maioria dos casos, manifestada através do uso de mais de uma língua” Brasil (1998, p.23).

E por fim, especifica e diferenciada a partir do momento que é concebida e planejada como reflexo das aspirações particulares de povo indígena e com autonomia em relação a determinados aspectos que regem o funcionamento e orientação da escola não-indígena.

A Constituição de 1988 trouxe garantias explícitas aos povos indígenas, O parágrafo $2^{0}$ do artigo 210 garante que "O ensino fundamental regular será ministrado em língua portuguesa, assegurada às comunidades indígenas também a utilização de suas línguas maternas e processos próprios de aprendizagem. Bendazolli (2011, p. 147) considerou a constituição de 1988 um marco especial de importância para os povos indígenas, "na medida que ela delimitou o fim da tutela e o início do direito à manutenção de suas línguas e cultura, de se manterem índios, com suas formas próprias de organização social”.

A Constituição Federal abriu caminho para que a Educação Escolar Indígena conquistasse novas estruturas legais e conceituais, que levaram a elaboração de novas leis, resoluções, diretrizes e pareceres direcionadas as sociedades indígenas na perspectiva de uma educação escolar especifica, diferenciada e intercultural, como podemos identificar com a publicação do Decreto n. 26/91 (BRASIL, 1991a), por este mecanismo o Governo Federal oficializou a transferência da coordenação da educação escolar indígena da Funai para o MEC, assim Estados e Municípios tornam-se responsáveis da educação escolar indígena. A Portaria Interministerial n. 559/91 (BRASIL, 1991b), também auxiliou nesse processo de transformação ao modificar a concepção da educação escolar para as comunidades indígenas quando afirmou que essa deixa de ter um caráter integracionista.

Amparado na constituição de 1988, temos a Lei de Diretrizes e bases da Educação Nacional 9.394 de 20 de dezembro 1996 - LDB que trouxe em seu texto garantias explícitas para educação escolar indígena. Segundo Barros (2015, p. 45),

Essa nova lei garantia o reconhecimento dos direitos dos índios de forma constitucional, a fim de manter sua identidade cultural, o que fortaleceu os povos indígenas em suas organizações ao afirmar princípios que norteariam tacitamente o uso da língua materna e os processos próprios de aprendizagem nas escolas indígenas. 
Podemos observar essas garantias no Título VIII - Das Disposições Gerais -, art. 78 e 79.

Art. 78. O Sistema de Ensino da União, com a colaboração das agências federais de fomento à cultura e de assistência aos índios, desenvolverá programas integrados de ensino e pesquisa, para oferta de educação escolar bilíngue e intercultural aos povos indígenas, com os seguintes objetivos:

I - proporcionar aos índios, suas comunidades e povos, a recuperação de suas memórias históricas; a reafirmação de suas identidades étnicas; a valorização de suas línguas e ciências;

II - garantir aos índios, suas comunidades e povos, o acesso às informações, conhecimentos técnicos e científicos da sociedade nacional e demais sociedades indígenas e não-índias.

Art. 79. A União apoiará técnica e financeiramente os sistemas de ensino no provimento da educação intercultural às comunidades indígenas, desenvolvendo programas integrados de ensino e pesquisa.

$\S 1^{\circ}$ Os programas serão planejados com audiência das comunidades indígenas.

$\S 2^{\circ}$ Os programas a que se refere este artigo, incluídos nos Planos Nacionais de Educação, terão os seguintes objetivos:

I - fortalecer as práticas socioculturais e a língua materna de cada comunidade indígena;

II - manter programas de formação de pessoal especializado, destinado à educação escolar nas comunidades indígenas;

III - desenvolver currículos e programas específicos, neles incluindo os conteúdos culturais correspondentes às respectivas comunidades;

IV - elaborar e publicar sistematicamente material didático específico e diferenciado.

$\S 3^{0}$ No que se refere à educação superior, sem prejuízo de outras ações, o atendimento aos povos indígenas efetivar-se-á, nas universidades públicas e privadas, mediante a oferta de ensino e de assistência estudantil, assim como de estímulo à pesquisa e desenvolvimento de programas especiais. (Incluído pela Lei nº 12.416, de 2011).

Posterior a LDB, foram aprovados em 14.09.1999 as Diretrizes Curriculares Nacionais da Educação Escolar Indígena por meio do parecer 14/99 da Câmara Básica do Conselho Nacional de Educação, normatizado pela Resolução 03/99, sobre esse parecer Grupioni (2008), enfatiza a importância do parecer pois o mesmo institui as diretrizes, a proposição da 
categoria escola indígena, a definição de competências para a oferta da educação escolar indígena, a formação do professor indígena, o currículo da escola e sua flexibilização.

No que diz respeito a parecer CNE/CEB 14/99 e a resolução CEB 03/99, Cohn (2005, p. 489) enfatiza que,

Essas disposições reafirmam o reconhecimento administrativo da categoria escola indígena no sistema de ensino, a ênfase na formação de professores indígenas e produção de materiais didáticos específicos, o reconhecimento de programas e currículos específicos, a adaptação do projeto escolar à realidade indígena a que se volta e a criação de condições de autonomia e auto-gestão desses projetos escolares.

Cria-se, assim, as condições legais, jurídicas e administrativas, inclusive com a atribuição de competências e o reconhecimento de uma categoria especial no sistema de ensino, para a implantação da educação diferenciada e específica para os índios. Por ela, devese assegurar a inclusão da língua, da cultura e dos saberes indígenas no projeto curricular dessas escolas e o respeito à particularidade étnica e cultural dessas populações, reunindo alunos e professores de mesma etnia em seu projeto, execução e gestão. E a escola indígena passa a ser definida como diferenciada, específica, bilíngue e intercultural.

\section{Aspectos históricos da educação escolar indígena em Roraima}

O Estado de Roraima, unidade federativa mais ao norte do país, possui uma extensão territorial de $224.300,506 \mathrm{~km}^{2}$, sua capital Boa Vista é a única capital do país totalmente acima da linha do equador. O território do Estado está dividido em 15 municípios, com uma população total de 450.479 habitantes. O Estado possui a menor densidade demográfica do país com 2,01hab $/ \mathrm{km}^{2}$. Do total dessa população, 284,313 pessoas vivem na capital Boa Vista o que representa pouco mais $63 \%$ da população total do Estado (FREITAS, 2012).

Segundo o Censo (2010), Roraima é um Estado formado por uma grande diversidade cultural, o que inclui migrantes de todos os Estados da federação e populações indígenas. Estes últimos, representam cerca de $11 \%$ da população do Estado, sendo que cerca de $83 \%$ dessa população habitam em 32 Terras Indígenas sendo elas: Ananás, Anaro, Aningal, Anta, Araçá, Barata Livramento, Bom Jesus, Boqueirão, Cajueiro, Canauanim, Jabuti, Jacamim, Malacacheta, Mangueira, Manoa, Moskow, Muriru, Ouro, Trombetas/Mapuera, Pium, Ponta da Serra, Raimundão, Raposa Serra do Sol, Santa Inez, São Marcos, Serra da Moça, Sucuba, Tabalascada, Truaru, WaiWái, Waimiri-Atroari, Yanomami. Essas terras juntas, representam 
46,24\% do total da área do Estado, sendo que as maiores são a Terra Indígena Yanomâmi, que abriga os povos Yanomami e Yekuana, e a Terra Indígena Raposa Serra do Sol, que é habitada pelos povos Makuxi, Wapixana, Taurepang, Patamona e Ingarikó.

O censo demográfico 2010 inovou ao introduzir um conjunto de perguntas especificas para as pessoas que se declararam indígenas, como o povo ou a etnia a que pertenciam, como também, as línguas indígenas faladas, e nessa pesquisa segundo o censo demográfico 2010 podemos encontrar no Estado de Roraima além das tradicionais etnias Macuxi, Wapichana, Taurepang, Ingarikó, Patamona, Wai-Wai, Waimiri-Atroari, Yekuana e Yanomami, o censo também indentificou a presença de mais 19 etnias que são: Ninám, Apolima-Arara, Jarawara, Xavante, Karafawyana, Mawayana, Tenetehara, Xereu, Kahyana, Katuena, Karijo, Sanumá, Sateré-Mawe, Baré, Jaricuna, Kanela, Tukano, Arikapu e Guarani.

Logo abaixo apresento o mapa de Roraima com suas terras indígenas.

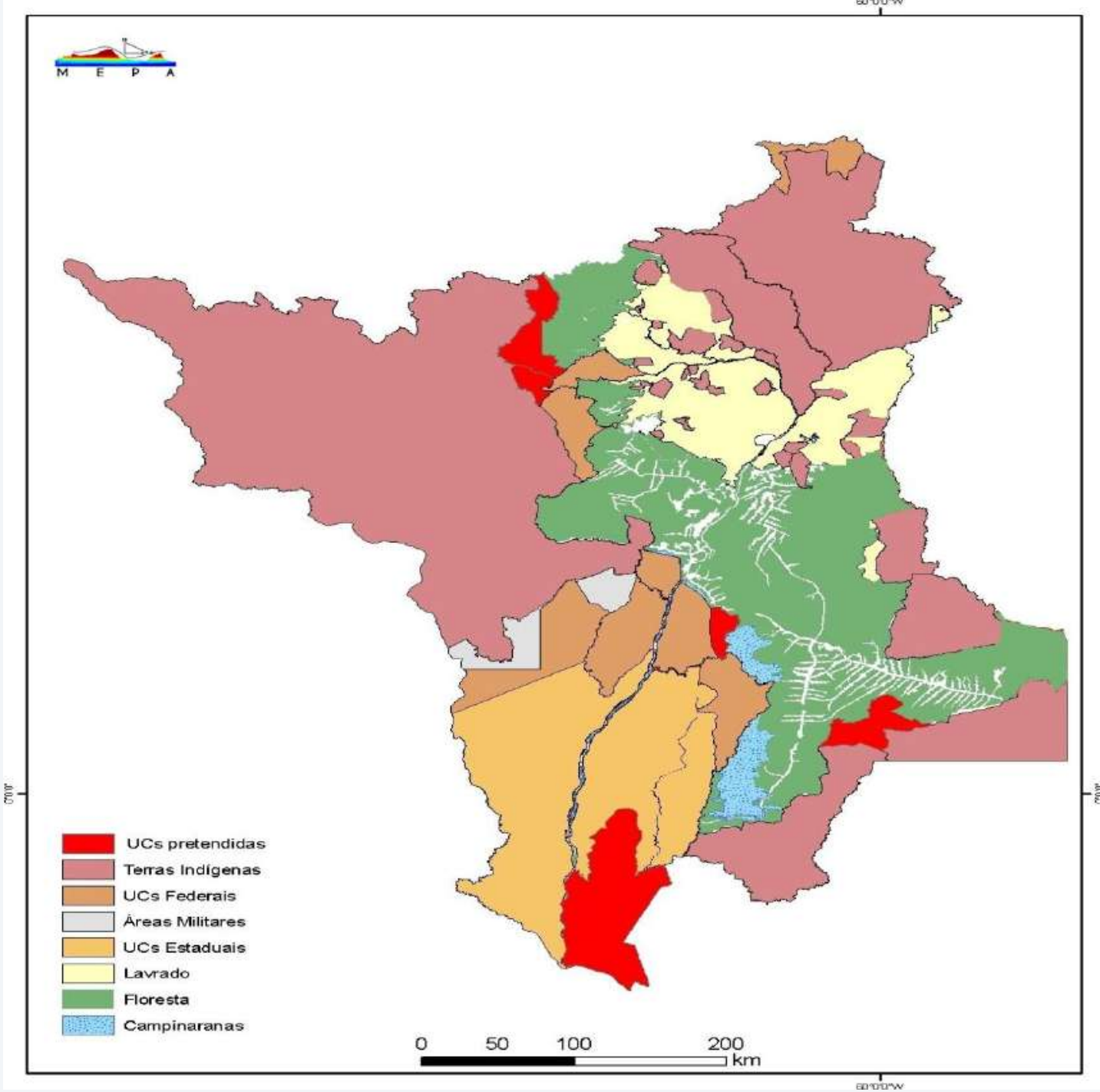

Fonte: http://ufrr.br/mepa/images, 2014. 
Enfatiza-se que quanto à participação relativa de indígenas no total da população dos Estados, Roraima detém o maior percentual.

Tabela 1. População Autodeclarada Indígena por Estado

\begin{tabular}{|l|c|}
\hline \multicolumn{2}{|c|}{ Proporção da População Autodeclarada Indígena por Estado } \\
\hline Unidades da Federação & No Total da População do Estado (\%) \\
\hline Roraima & $11 \%$ \\
\hline Amazonas & $4,8 \%$ \\
\hline Mato Grosso do Sul & $3,0 \%$ \\
\hline Acre & $2,2 \%$ \\
\hline Mato Grosso & $1,4 \%$ \\
\hline Amapá & $1,1 \%$ \\
\hline Tocantins & $0,9 \%$ \\
\hline Rondônia & $0,8 \%$ \\
\hline Pernambuco & $0,6 \%$ \\
\hline Maranhão & $0,5 \%$ \\
\hline
\end{tabular}

Fonte: Censo 2010

Outro dado importante encontrado no censo 2010, é que dentre os 10 municípios que apresentaram maior proporção de indígenas no total da população, nos últimos 10 anos, 4 municípios estão localizados no Estado de Roraima, sendo que o maior percentual foi encontrado no Município de Uiramutã com $88,1 \%$ de sua população sendo indígena.

Tal afirmação fica mais observável na tabela abaixo.

Tabela 2. Maior Proporção da População Indígena por Município

\begin{tabular}{|l|c|c|}
\hline \multicolumn{1}{|c|}{ Unidades da Federação } & Municípios & $\begin{array}{c}\text { Maiores Proporção da } \\
\text { População Indígena (\%) }\end{array}$ \\
\hline Roraima* & Uiramutã & 88,1 \\
\hline Paraíba & Marcação & 77,5 \\
\hline Amazonas & São Gabriel da Cachoeira & 76,6 \\
\hline Paraíba & Baía da Traição & 71,0 \\
\hline Minas Gerais & São João das Missões & 67,7 \\
\hline Amazonas & Santa Isabel do Rio Negro & 59,2 \\
\hline Roraima* & Normandia & 56,9 \\
\hline
\end{tabular}




\begin{tabular}{|l|c|c|}
\hline Roraima* & Pacaraima & 55,4 \\
\hline Acre & Santa Rosa do Purus & 53,8 \\
\hline Roraima* & Amajari & 53,8 \\
\hline
\end{tabular}

Fonte: Censo 2010

Diante do exposto, percebemos a grande diversidade étnica e cultural que se apresenta no estado de Roraima, diversidade esta que se constitui como um desafio para a implementação de políticas públicas destinadas a essa população, sobretudo, no que diz respeito à educação escolar específica e diferenciada de base e princípio intercultural. Tal desafio se dá em virtude do grande número de povos, bem como às condições de acesso a estes. No entanto, é importante salientar que mesmo existindo dificuldades, os povos indígenas vêm garantindo o acesso à educação.

A história da educação escolar para os povos indígenas no estado de Roraima não foi diferente do resto do país, segundo Nascimento (2014, p. 93) "ali a ação educacional e seus impactos sobre estas populações foram tão nefastas quanto em outras regiões, apesar de ter começado tardiamente". Segundo o autor, em Roraima, as primeiras escolas que se tem notícia, datam do início do século passado, e foram destinadas prioritariamente às populações indígenas da região. Tais escolas foram instaladas em um primeiro momento pelos missionários beneditinos, que chegaram à região no ano de 1909 e aí permaneceram até o ano de 1947, e posteriormente pelo Serviço de Proteção aos índios (SPI) que neste período também se instalou na região.

Identifica-se que as escolas implantadas pelos missionários beneditinos tinham como principal objetivo promover a "civilização" dos povos indígenas. Para os missionários, "criar escolas primárias nas zonas habitadas pelos silvícolas, para que estes se adaptassem aos costumes da civilização" era de certa forma, uma maneira de torna-los úteis ao engrandecimento da nação.

Pode-se dividir em dois grandes períodos a educação escolar indígena, sendo o primeiro período da educação escolar indígena em Roraima iniciado nos anos 1909, com a chegada da missão Beneditina na região e se estende até 1947 quando de sua saída definitiva da região e o segundo período iniciado em 1948, quando da instalação da Missão Consolata, em substituição aos beneditinos e se prolonga até a atualidade.

Frente ao exposto, percebe-se que a educação para índios em Roraima, nasceu sob os auspícios da Igreja Católica, sua filosofia pedagógica estava orientada para o ensino da língua portuguesa e ao processo de catequização. 
Assim como no restante do Brasil, a década de 1970 também foi marcada em Roraima pela luta dos povos indígenas pela sua independência e reconhecimento como parte da nação.

Em 1990, os professores de Roraima, realizaram um encontro na missão Surumu, que reuniu professores Makuxi, Wapixana, Taurepang e Ingarikó. Este encontro tinha como objetivo fortalecer a luta na defesa de uma educação escolar que viesse atender às demandas crescentes das comunidades indígenas. Foi, portanto, nesse encontro que nasceu a OPIR Organização dos Professores Indígenas de Roraima.

Apesar de conhecerem seus direitos e saberem, em tese, o que seja uma educação escolar diferenciada, os professores indígenas encontram durante anos dificuldades para que esta educação deixe de ser uma proposta para se tornar realidade. Os principais obstáculos encontrados foram a falta de capacitação/formação continuada; ausência de currículo que estabeleça o que deva ser ensinado no que concerne à língua e à cultura indígena; falta de materiais didáticos que norteiem o trabalho desses profissionais em sala de aula.

Esse quadro vem modificando aos poucos, no estado de Roraima as questões relacionadas à educação escolar indígena têm ganhado grande visibilidade na última década. Após meio século de reivindicação, os povos indígenas de Roraima, podem dizer que hoje a Educação Escolar Indígena Especifica e Diferenciada, Bilíngue e Intercultural foi finalmente implantado, tornando-se uma realidade do ponto de vista normativo.

Atualmente a educação escolar indígena conta com organismo que se articulam e fortalecem todo o processo educacional. Em nível de Secretaria Estadual de Educação temos o Divisão de Educação Escolar Indígena - DIEI que é responsável pela lotação dos professores indígenas em sala de aula, pelas orientações pedagógicas aos coordenadores indígenas, encaminhamento da merenda escolar, bem como elaboração das rotas para o transporte escolar, outro órgão importante é o Centro Estadual de Formação dos Profissionais da Educação de Roraima - CEFORR, tal órgão tem como missão efetivar a formação inicial e continuada dos profissionais da educação de Roraima, sendo assim o CEFORR disponibiliza o Projeto Tamikan que é um curso de formação inicial em nível de magistério indígena, que tem como finalidade habilitar professores indígenas para exercerem suas atividades docentes na Educação Infantil e series iniciais do Ensino Fundamental nas escolas inseridas na comunidades indígenas.

Projeto Yarapiari é um curso de formação no Ensino Fundamental e Ensino Médio Magistério para professores indígenas oriundos das Terras Indígenas Yanomami, o curso tem como objetivo promover o exercício da cidadania do povo Yanomami, além de constituir um 
quadro de docentes capazes de desenvolver escolas multilíngues fundamentadas nos processos próprios de aprendizagem.

Projeto Línguas Maternas Murumurutá é voltado para capacitação de professores indígenas nas línguas maternas, pertencentes as etnias: Macuxi, Ingarikó, Taurepang e Wapapixa. A capacitação terá por finalidade preparar os professores falantes de línguas maternas para irem além da oralidade, uma vez que ainda há uma necessidade de termos bons escritores, capazes de planejar um texto a ter o domínio das palavras e suas combinações.

Roraima também conta com o Núcleo Insikiran de Formação Superior Indígena, o núcleo dispõe da Licenciatura Intercultural, o objetivo do curso é formar e habilitar professores indígenas em Licenciatura Plena com enfoque intercultural, nas áreas de concentração em Ciências Sócias, em Comunicação e Artes ou em Ciências da Natureza.

Percebe-se que hoje a formação dos professores é uma das principais preocupações das lideranças indígenas, não significa dizer que os professores acreditem que somente sua formação garantirá a qualidade do ensino nas comunidades, mas que esta é um dos meios de acesso a essa qualidade.

\section{Importância do material didático para comunidades indígenas}

As escolas, hoje, possuem inúmeros meios de dar suporte aos ensinamentos transmitidos aos alunos e isso faz toda a diferença na forma transmissão do conhecimento. Livros, apostilas, e-books, equipamentos eletrônicos de última geração, tudo vem ao encontro de uma aprendizagem mais eficaz, que garanta ao aluno reter melhor os conteúdos e aprimorá-los.

O material didático colabora para a transformação social na medida em que favorece a elaboração constante do conhecimento como resultado de experiências interativas, propiciando o crescimento de um cidadão criativo, crítico e produtivo, pronto a enfrentar a vida com mais segurança.

Como mencionado anteriormente, os povos indígenas lutaram durantes séculos pelo reconhecimento da sua condição de índio. Pelo respeito a sua cultura e por uma educação escolar que representasse seu povo.

A parti dos contextos das reformas educativas desencadeadas a partir da década de 1990 em diversas partes do mundo e atendendo a reivindicações do movimento indígena e indigenista em prol de processos de escolarização diferenciada, o Estado brasileiro publicou o 
Referencial Curricular Nacional para as Escolas Indígenas (1998) e a Coleção de livros didáticos do Referencial Curricular Nacional para as Escolas Indígenas (1998). Estes documentos, entre outros, procuraram delinear uma proposta oficial para a construção de currículos e materiais didáticos específicos na direção da efetivação de práticas pedagógicas diferenciadas.

Conforme orientações do RCNEI, a construção de materiais didáticos deve ser realizada a partir de pesquisas nas comunidades, especialmente junto aos mais velhos, considerados detentores dos saberes e histórias tradicionais dos grupos, e de experiências vividas em sala de aula em diálogo com as disciplinas escolares. O espaço privilegiado para a construção dos materiais específicos são os cursos específicos de formação de professores indígenas.

Alguns professores indígenas explicitam a importância do material didático condizente coma realidade da comunidade.

As dificuldades que vivemos para construir esta escola diferenciada é que não temos livros diferentes. Os que temos são iguais aos da cidade e não falam de nossos povos indígenas... Este problema pode ser superado através da produção de livros nossos... Em cursos deformação e capacitação. Maria José Lima, Professora Xucuru, PE. (BRASIL, 1998a, p. 80,).

Outro professor indígena também relata que,

O que eu tenho dificuldade é para me esclarecer mais e desenvolver o trabalho da minha história. Para passar dentro da minha escola indígena, para meus filhos que estão presentes dentro da área indígena. E inclusive elaborar uma cartilha para nós ensinarmos nossos filhos e os nossos netos que estão nascendo daqui para frente. Por isso, eu estou interessado em pesquisar a minha história, música de mariri, cipó, pescaria, caçada, sonho, batismo, gavião etc. E para registrar no cartório para não se acabar mais. Como era a história de antigamente e a história do passado. Ex: o conhecimento do nosso avô, de 1940, como nossos parentes eram no tempo de cativeiro. Neste ano eu vou pesquisar nos outros lugares onde nossos parentes estão morando no Peru. Eu, professor, penso no futuro em construir mais material didático dentro de área indígena para nossos alunos aprenderem. Paulo Siã, professor Kaxinawá, AC. (BRASIL, 1998a, p. 82,).

A partir desses relatos, nota-se a preocupação de tais professores pela elaboração de materiais didáticos que represente suas comunidades. Percebe-se uma grande preocupação em conta sua história através dos livros didáticos, de ensinar suas músicas, seus rituais.

O material didático para os professores indígenas, é muito mais do que um simples guia de condução pedagógica dentro de sala como funciona muitas vezes nas escolas não 
indígenas. Esse material tem como objetivo o fortalecimento de uma cultura historicamente desprezada.

Na ocasião da publicação do RCNEI, o Ministério da Educação e Cultura financiou a publicação da coleção de livros didáticos do Referencial Curricular Nacional Para as escolas indígenas, elaborados a partir das experiências acima mencionadas. A coleção foi distribuída nas escolas indígenas juntamente com cópias do RCNEI. Estes livros tratam-se de:

[...] coleção de livros elaborados por professores de diferentes etnias, pretendendo oferecer referências, exemplificando como é possível a construção de material didático de qualidade adequado a cada comunidade indígena, e ao mesmo tempo, iniciar um intercâmbio entre os diferentes povos e escolas indígenas do país. (BRASIL, 1998b, p. 07).

Embora a elaboração de materiais didáticos específicos que contemple, entre outros aspectos, a sistematização de saberes próprios seja considerada uma das condições da escola indígena, verifica-se a quase inexistência de materiais específicos cerca de 20 anos depois da Constituição Federal de 1988 e 10 anos depois da publicação do Referencial Curricular Nacional das Escolas Indígenas.

De modo geral, estas publicações dizem respeito, entre outros, a aspectos da história, da língua e da dinâmica cultural local. Ou seja, foram produzidos a partir de conhecimentos locais ou cotidianos.

\section{Experiência docente na Escola Estadual Indígena Riachuelo}

A Escola Estadual Indígena Riachuelo está localizada, na comunidade indígena do Sucuba, município do Alto Alegre, Estado de Roraima. A referida escola localiza-se a 55 quilômetros da cidade de Boa Vista capital do Estado de Roraima.

Segundo dados do censo demográfico de 2010 a comunidade do Sucuba tinha uma população estimada em 213 habitantes, sendo 44,1\% mulheres e 55,9\% homens, sua população conta com índios das etnias Wapixana, Makuxi e Xavante, as línguas indígenas que são faladas na comunidade são Makuxi e Chamakóko sendo que apenas 17,8\% dos moradores da comunidade falam tais línguas.

Tive o mérito de trabalhar com docente nesta comunidade, mais precisamente na Escola Estadual Indígena Riachuelo nos anos de 2010 e 2011. 
Segundo dados do censo escolar 2016 a escola estadual indígena Riachuelo, conta com um total de 175 alunos, divididos na modalidade de ensino fundamental, ensino médio e educação de jovens e adultos.

Além da disciplina de Educação Física, ministrei aulas nesta escola nas disciplinas de história e biologia tanto no ensino fundamental e médio. Participei de reuniões de comunidade, comemorações festivas da comunidade e da escola, jogos indígenas da amizade, entre outros eventos.

Antes de aprofundar o debate de como ocorriam as aulas e como eram os materiais didáticos utilizados no decorrer das aulas, quero primeiro abrir um parágrafo e esclarecer, algo, pois é de essencial importância enfatizar, que na minha formação acadêmica não tive nenhuma experiência com educação escolar indígena, simplesmente nada, nem legislação, nem cultura indígena. Fica claro então que adentrei na comunidade com uma visão estereotipada e errônea sobre os indígenas, pois tinha desconhecimento total sobre a cultura ou mesmo a educação escolar indígena.

Retomando sobre a descrição dessa experiência magnifica dentro da Escola Estadual Indígena Riachuelo, tive que passar por algumas etapas. A primeira delas e a mais importante no meu ponto de vista foi ser aceito pela comunidade. Como assim aceito pela comunidade? Bem é assim, para se trabalhar dentro de uma comunidade indígena você precisa passar por uma reunião da comunidade, onde todos os membros dessa comunidade devem de maneira democrática realizar uma votação dizendo se aceitam um indivíduo não indígena ministrando aulas dentro de sua comunidade. Fica claro que a decisão não é monocrática do tuxaua da comunidade.

Após ser aceito pela comunidade o segundo passo foi participar do encontro pedagógico junto com os outros professores da comunidade e auxiliar na elaboração do calendário escolar, foi nesse momento que tomei conhecimento que o calendário escolar das escolas indígenas não é o mesmo das escolas não indígenas, pois alguns feriados não são considerados nesse calendário, bem como dias de colheita são consideradas como atividades letivas, pois naquele momento de colheita considera-se que está ocorrendo aprendizagem. Cabe ressaltar a participação efetiva dos pais ou responsáveis pelos alunos na elaboração do calendário acadêmico, ficou evidenciado que a comunidade participava de todas as decisões e auxiliava na organização da vida escolar dos alunos, não cabendo só ao corpo docente a formulação da proposta acadêmica. 
Logo após essas duas etapas comecei a elaborar meus planos de aula das disciplinas de História e Biologia, utilizando como referência para elaboração desses planos os Parâmetros Curriculares Nacionais das escolas não indígenas. Isso mesmo os Pcn's que regem a formulação dos currículos das escolas não indígenas.

Apesar de ter participado de encontros pedagógicos nunca fiquei sabendo do Referencial Curricular Nacional das Escolas Indígenas.

Fica claro aqui que nesses dois anos de docência trabalhei única e exclusivamente com o mesmo material didático utilizado nas escolas não indígenas. As apostilas que eram elaboradas não sofriam nenhum tipo de adequação a realidade da comunidade. Os objetivos propostos nos planos de aula bem como os mecanismos de avaliação seguiam os moldes sugeridos para escolas não indígenas.

Os textos apresentados em sala de aula apresentavam uma realidade muito distante daquela que era vivido pelos alunos, não considerava as questões culturais da comunidade, exemplos de organização social e econômica que poderiam ser muito bem exploradas nas aulas de história, aspectos do cultivo de plantas e animais que poderiam ser muito bem relacionadas nas aulas de biologia.

Ainda no que diz respeito a disciplina de biologia, perdeu-se uma grande oportunidade de se utilizar como material didático as características da própria comunidade, pois todos os alunos ajudavam seus pais no cultivo da mandioca, e no momento da aula poderia se debater formas de fertilizar o solo para o plantio, formas de irrigação, propriedades da água, ou seja aulas expositivas que enriqueceriam o debate acadêmico.

Em meus planos de aula, nunca houve uma preocupação em relacionar mesmo que minimamente os conteúdos propostos com a língua materna falada na comunidade, não se enxergava a importância que a língua materna tinha para comunidade. A história de um povo é contada através de sua língua materna, como os antepassados se comunicavam, como nomeavam coisas a sua volta, como se nomeava os seres, as crenças e as lendas que motivavam suas vidas.

Enfim o que se apresentava era uma realidade nada condizente com a realidade dos alunos, fato esse que talvez justifique a falta de motivação dos alunos em sala de aula.

No primeiro ano de trabalho na escola indígena Riachuelo, o índice de reprovação nas disciplinas de biologia e história foi altíssimo, os alunos relatavam dificuldades de compreender o conteúdo, alguns professores indígenas questionavam a metodologia que 
utilizava em sala de aula, para esses professores as aulas deviam representar a realidade dos alunos indígenas e não a realidade de alunos de centros urbanos.

Em reunião com os responsáveis dos alunos, por diversas vezes fui questionado sobre o material que era utilizado no decorrer das aulas, os pais manifestavam certa insatisfação, pois acreditavam que não poderia utilizar apenas apostilas e livros da cidade para ministrar as aulas, mas como enfatizei anteriormente não conseguiu compreender a necessidade de um trabalho intercultural em sala de aula.

\section{Considerações finais}

Após o levantamento de literatura associada a experiência vivida ao longo de dois anos na Escola Estadual Indígena Riachuelo considero de suma importância pontuar alguns aspectos.

Toda transformação positiva ocorrida para os povos indígenas não foi de graça, foi fruto de um longo período de mobilização, articulação e lutas em todo cenário nacional, os benefícios adquiridos e gozados no presente pelos povos indígenas foram graças a insistência de seus ancestrais na luta pelo reconhecimento de suas diferenças enquanto índio.

Dentre esses benefícios posso citar a valorização da educação escolar indígenas na Base Nacional Curricular Comum, a BNCC ao se referir a educação escolar indígena, assegurou os princípios da coletividade, reciprocidade, integralidade, espiritualidade e alteridade indígena, a serem desenvolvidas a partir de suas culturas tradicionais reconhecidas nos currículos dos sistemas de ensino e propostas pedagógicas das instituições escolares. Significa também, em uma perspectiva intercultural, considerar seus projetos educativos, suas cosmologias, suas lógicas, seus valores e princípios pedagógicos próprios em consonância com a Constituição Federal.

A Lei 11.645 , de 10 de março de 2008 que trouxe em seu texto a inclusão obrigatória nos estabelecimentos de ensino fundamental e médio, públicos e privados o estudo da história e cultura afro-brasileira e indígena, deixando claro a importância de se trabalhar os aspectos culturais dos afro-brasileiros e dos povos indígenas desde as series iniciais da educação básica.

Outro aspecto que penso ser necessário destacar, é a importância que os cursos de licenciatura abordem não de maneira simplista, mas com abrangência as temáticas voltadas para educação escolar indígena, visto que, os professores devem ser capacitados para 
trabalhar com esse público dentro e fora das comunidades indígenas, haja vista que é cada vez mais comum encontrarmos indígenas dentro das escolas dos grandes centros urbanos.

Enfatiza-se também a importância dos professores que forem atuar dentro das escolas indígenas sejam professores indígenas, pois os mesmos conhecem a realidade da comunidade, respeitando e valorizando a cultura local, aplicando mais adequadamente na sua práxis pedagógica os conteúdos acadêmicos.

No último processo seletivo realizado pela Secretaria Estadual de Educação de Roraima para contratação de professores indígenas através do edital PSS/SEED/GAB/RR $n^{\circ}$ 001/2017, foi exigido como pré-requisito para investidura no cargo a apresentação do Registro Administrativo de Nascimento Indígena - RANI, fornecido pela FUNAI, dessa forma coloca-se em prática as normas legais estabelecidas pela resolução CNE no 03/99 no que diz respeito aos professores da educação escolar indígena serem prioritariamente indígenas.

Relacionada ao material didático especifico e diferenciado tema que foi o objetivo desse artigo, considero de suma importância a utilização dentro das escola indígenas de material didático que represente a comunidade, que estes matérias tragam aspectos culturais da comunidade onde os mesmo devem ser relacionados com os conteúdos propostos em sala de aula, não se pode mais aceitar que passados mais de 20 anos da promulgação da LDB as escolas indígenas ainda utilizem única e exclusivamente material didático que não os represente, que não tragam nenhum tipo de significação para eles.

Acredito que os indígenas devem ser os autores de seus próprios manuais escolares, os índios podem elaborar seus materiais didático-pedagógicos levando em consideração características específicas de um dado povo indígena e da própria educação escolar indígena, também podem produzir livros didáticos mais contextualizados a realidade de sua educação e as necessidades do próprio professor na sala de aula e, ainda, livros isentos de preconceitos, generalizações ou estereótipos comuns aos povos indígenas.

Infelizmente a maioria das escolas indígenas do estado de Roraima, ainda conta como material didático apenas os livros didáticos fornecidos pelo Programa Nacional do Livro Didático - PNLD, ou seja, os mesmos livros que são distribuídos nas escolas não indígenas, nesse sentindo constata-se que é necessário avançar no sentido de estimular a produção de material didático dentro das comunidades indígenas, objetivando uma melhoria na qualidade de ensino. 


\section{REFERÊNCIAS}

BARROS, J. L. da C. O brincar e suas relações interculturais na escola indígena. 1. ed. Curitiba: Appris, 2015.

BENDAZZOLI, S. Políticas públicas de educação escolar indígena e a formação de professores Ticunas no Alto Solimões/AM. Tese (Doutorado em Educação) - Universidade de São Paulo, São Paulo, SP.

BERGAMASCHI, M. A. Educação Escolar Indígena: Um modo próprio de recriar a escola nas aldeias Guarani. Caderno Cedes, Campinas, v. 27, n. 72, 2007.

BRASIL. Constituição da República Federativa do Brasil: promulgada em 5 de outubro de 1988. São Paulo: Saraiva, 2005.

BRASIL. IBGE. Disponível em: 〈http://www.censo2010.ibge.gov.br/terrasindigenas/> . Acesso: em 01 de fev. 2018.

BRASIL. Lei 11.645, de 10 março de 2008. Disponível em: <http://www.planalto.gov.br/ccivil_03/_ato2007-2010/2008/lei/111645.htm>. Acesso: em 01 de fev. 2018

BRASIL. Lei 9.394, de 20 de dezembro de 1996. Lei de Diretrizes e Bases da Educação Nacional. Brasília: MEC, 1996.

BRASIL. Ministério da Educação e do Desporto. Secretaria de Educação Fundamental. Referencial Curricular Nacional para as Escolas Indígenas. Brasília, DF:

MEC/SEF,1998a.

BRASIL. Ministério da Educação e do Desporto. Secretaria de Educação Fundamental. Coleção de livros didáticos do Referencial Curricular Nacional para as Escolas Indígenas: informações para o professor. Brasília, DF: MEC/SEF, 1998 b.

BRASIL. Parecer CNE n. 14/99 - CEB, aprovado em 14 de setembro de 1999, sobre as diretrizes curriculares nacionais da educação escolar indígena. Brasília: CNE/CEB, 1999.

COHN, C. Educação escolar indígena: para uma discussão de cultura, criança e cidadania ativa. Perspectiva, Florianópolis, v. 23, n.02, p. 485-515, 2005.

DUARTE, S. V; FURTADO, M. S. V. Trabalho de conclusão de curso: TCC em Ciências Sociais Aplicadas. São Paulo: Saraiva, 2015.

FREITAS, A. Geografia e história de Roraima. 8 ed. Boa Vista: IAF, 2012.

GRUPIONI, L. D. B. Olhar longe, porque o futuro é longe: cultura, escola e professores indígenas no Brasil. 2008. 240 fl. Tese de doutorado em Antropologia Social - USP, São Paulo, SP. 
MAPA INTERATIVO. Disponível em: 〈http://www.invistaemroraima.rr.gov.br $>$. Acesso em 13 de fev. 2018

MATRICULA E ESTRUTURA DA ESCOLA ESTADUAL INDIGENA RIACHUELO

QEDU. Disponivel em: <http://www.qedu.org.br/escola/7701-escola-estadual-indigenariachuelo/sobre>. Acesso: em 07 de set. 2017.

MINAYO, M. C. de S; colaboradores Suely Ferreira Deslandes et al. Pesquisa social: Teoria, método e criatividade. Petrópolis: Vozes.

NASCIMENTO, R. N. F. Interculturalidade e educação escolar indígena em Roraima: da Normatização a Prática Cotidiana. 2014. 266fl. Tese (Doutorado em Antropologia). Programa de Pós-Graduação da Universidade Federal de Pernambuco, UFPE. Recife, PE.

\section{$\underline{\text { SOBRE OS AUTORES }}$}

\section{Paulo Weverton Soares Cizino de Paiva}

Mestrando em Educação pela Universidade Estadual de Roraima (UERR). Membro do Grupo de Estudos e Pesquisas em Educação, Interculturalidade e Emancipação Humana. E-mail: paulo_cizino@yahoo.com.br

\section{Maristela Bortolon de Matos}

Doutora em Educação pela Universidade do Vale do Rio dos Sinos (UNISINOS). Professora Titular do Instituto Federal de Educação, Ciência e Tecnologia de Roraima (IFRR). Docente do Programa de Pós-Graduação em Educação da Universidade Estadual de Roraima (UERR). Membro do Grupo de Estudos e Pesquisas em Educação, Interculturalidade e Emancipação Humana. E-mail: bortolondematos@yahoo.com.br 